\title{
«EL ASESINATO DEL CHANTRE DON VENTURA FERRER. CLÉRIGOS Y BANDOS EN LA SEO VALENTINA SEISCENTISTA»
}

\author{
POR \\ Emilio Callado Estela \\ Profesor Agregado. Universidad CEU Cardenal Herrera - Valencia
}

\begin{abstract}
RESUMEN
El clero de la Seo no fue ajeno a las bandositats que aglutinaron a buena parte de la sociedad valenciana durante el siglo XVII. Lo demuestra el caso del chantre don Ventura Ferrer, líder de una de las facciones catedralicias que, con el apoyo externo del bando de los Vallterra, luchaba por el control de la primera iglesia del reino. Frente a él, el grupo de canónigos patrocinado por el Almirante de Aragón, a la cabeza de la parcialidad contraria y responsable último del asesinato del chantre en 1661, suceso este que pondría al descubierto la imbricación entre el mundo eclesiástico y el fenómeno del bandolerismo.
\end{abstract}

Palabras ClaVE: Bandolerismo, eclesiásticos, catedral, Don Ventura Ferrer, siglo XVII.

\section{«THE MURDER OF THE PRECENTOR DON VENTURA FERRER. CLERGY AND FACTIONS IN THE CATHEDRAL OF VALENCIA»}

\begin{abstract}
The cathedral clergy did not remain aloof from the factions that drew together a major part of the Valencian society during the XVII century. A good example is the case of the precentor Don Ventura Ferrer, who led one of the cathedral sections and who, supported by the Vallterra family, sought the control of the first church of the kingdom. On the opposite side was the group of canons represented by the admiral of Aragón, head of the opposing supporters and liable for the precentor's murder in 1661 . This event revealed the overlapping of the ecclesiastic world and the phenomenon of banditry.
\end{abstract}



KEY WORDS: Banditry, ecclesiastics, cathedral, Don Ventura Ferrer, $17^{\text {th }}$
century.

$\begin{array}{ll}\text { Recibido/Received } & 16-11-2010 \\ \text { Aceptado/Accepted } & 28-02-2013\end{array}$

La historiografía de las últimas décadas ha insistido en la importancia que el bandolerismo, bajo sus diferentes especies, tuvo en la trayectoria social y política del Reino de Valencia a lo largo de la época moderna, y muy particularmente durante el siglo XVII. ${ }^{1}$ El impacto de tal fenómeno en el clero, sin embargo, continúa siendo un aspecto escasamente atendido por los especialistas en el tema, al menos en una de sus expresiones más características. Hablamos de las bandositats, parcialidades o bandos que aglutinaban a una gran parte de los valencianos y en las que el número y calidad de los eclesiásticos implicados no fue en absoluto despreciable. Se trataba a menudo de hombres de escasa vocación religiosa, ingresados en las filas del clero para hacerse con pingües beneficios o para obtener las ventajas inherentes al privilegium fori, lo que les eximía de la justicia ordinaria sin necesidad de renunciar a una vida seglar y poco honesta. ${ }^{2} \mathrm{Ni}$ siquiera los miembros de la principal iglesia del reino, destino para los vástagos de ilustres familias, fueron ajenos a estas facciones entorno a las

${ }^{1}$ Sin ánimo de exhaustividad, merecen ser citados en este particular los trabajos de García Martínez. S. 1980. Bandolers, corsaris i moriscos. Valencia: Tres i Quatre, y 1991. Valencia bajo Carlos II: Bandolerismo, reivindicaciones agrarias y servicios a la Monarquía. Valencia: Ayuntamiento de Villena; Casey. J. 1970 «La crisi general del segle XVII a València, 1646-1648». Boletín de la Sociedad Castellonense de Cultura XLVI: 96-173, 1983. El Reino de Valencia en el siglo XVII. Madrid: Siglo XXI, y 1988. «Bandos y bandidos en la Valencia Moderna», en Homenatge al doctor Sebastià Garcia Martínez: I 407-421. Valencia: Generalitat Valenciana; Salvador Lizondo. $M^{\mathrm{a}}$ D. 1986. Los virreinatos de los duques de Maqueda y Segorbe (1553-1563). Configuración del bandolerismo, presión islámica y problemática de sus gobiernos, Tesis doctoral inédita. Valencia: Universitat de València; Vila López, M. 1984. Bandolerismo y piratería (1635-1645) en el reino de Valencia, durante el reinado de Felipe IV. Valencia: Universitat de València; Felipo Orts. A. 1988. El centralismo de nuevo cuño y la política de Olivares en el País Valenciano. Valencia: Ayuntamiento de Valencia; Ferrero Micó. R. 1985. «Bandosidades nobiliarias en Valencia durante la época foral», Saitabi XXXV: 95-110; y Guía Marín. Ll. J. 1980. «La Guerra de Cataluña y el bandolerismo valenciano (1640-1652)», en Ier Colloque sur le Pays Valencien a l'époque moderne: 117-141. Pau: s.e, 1984. «Dissidència política i repressió social al País Valencià a mitjan segle XVII». Saitabi XXXIV: 105-124, 1994 «Rebels i marginats en el segle XVII valencià», en La Segona Germania. Col-loqui Internacional, Valencia: 65-132. Valencia: Diputació de València, 2002. «Dona, honor i bandolerisme: els desordres de l'Almirall d'Aragó en la València del segle XVII». Estudis 28: 287-315, y 2003. «Bandoleros, rebeldes y marginados: Mateu Vicent Benet y las bandositats valencianas», en Banditismi mediterranei (secoli XVI-XVII): 87-106. Cerdeña.

${ }^{2}$ Callado Estela. E. 2003. Inmunidad eclesiástica y delincuencia en el siglo XVII. Los arzobispos de Valencia y la pacificación del Reino (1612-1699). Valencia: Biblioteca Valenciana.

Hispania Sacra, LXVI

133, enero-junio 2014, 109-131, ISSN: 0018-215X, doi: 10.3989/hs.2013.048 
cuales se alineaban muchos de sus parientes. Pocas veces se haría tan evidente la imbricación de ambos mundos como en el caso del chantre de la Catedral de Valencia don Ventura Ferrer, asesinado en 1661.

No es mucho lo que sabemos de este clérigo antes de su desaparición. Venido al mundo allá por el año 1627, en el seno de uno de los linajes de la pequeña nobleza, era nieto de don Enrique Ferrer y doña Ana Crespí, hermana de don Francisco Crespí de Valldaura, y por tanto tía del futuro vicecanciller del Consejo de Aragón don Cristóbal Crespí. ${ }^{3}$ Sus padres, don Jerónimo Ferrer y doña Vicenta Milán, tuvieron varios hijos, entre ellos una mujer, de nombre doña Ana Margarita, y otro varón además de nuestro protagonista, llamado don Francisco. ${ }^{4}$

A los dieciocho años, y sin haberse ordenado sacerdote como todo parece indicar, don Ventura obtenía una bula otorgada en Roma sexto nonas iulii anno $M D C X L V$ para incorporarse a la Catedral como chantre o cabiscol, una de las siete dignidades de la iglesia metropolitana a la que correspondía la organización del canto en el coro durante los oficios divinos. ${ }^{5}$ En el mes de noviembre de aquel mismo año 1645 Ferrer presentaba el documento pontificio para tomar posesión de esta prebenda. Lo hizo el día $27 .{ }^{6}$ Desde aquel momento, el nombre del chantre desaparecería de los registros documentales consultados durante algo más de una década, hasta que las cuitas internas de la Seo lo catapultaron a la mala fama, según se verá.

Pocas Iglesias de la Monarquía Hispánica escapaban al seminario de pleitos que, desde hacía al menos un siglo, constituían los cleros catedralicios. ${ }^{7}$ Una

\footnotetext{
${ }^{3} \mathrm{Al}$ respecto de esta saga Pons Alós. V. 1990. Los Crespí de Valldaura y l'Alcúdia de Crespíns. L'Alcúdia de Crespíns: Associació d'Amics de l'Ermita de Sumacàrcer; 1995. El señorío de Sumacàrcer en la Baja Edad Media. De mudéjares a moriscos. Sumacàrcer: L'Alcúdia de Crespíns: Associació d'Amics de l'Ermita de Sumacàrcer, y 1999. El señorío de Sumacárcer en el siglo XVII: la expulsión de los moriscos y la repoblación cristiana. Sumacàrcer: L'Alcúdia de Crespíns: Associació d'Amics de l'Ermita de Sumacàrcer.

${ }^{4}$ Biblioteca de la Real Academia de la Historia [=BRAH]. Salazar y Castro. Genealogías de familias valencianas, f. 2v, y Pons Alós. V. 1982. El fondo Crespí de Valldaura en el Archivo Condal de Orgaz (1249-1548): 38. Valencia: Universitat de València. Es muy posible que el tal don Francisco fuera el mismo Ferrer y Milán nombrado el 18 de septiembre de 1641 para cubrir la vacante canonical dejada por muerte de don Benito de Borja. Archivo de la Catedral de Valencia [=ACV]. Leg. 691, Llibre de possessions de l'arquebisbat, dignitats y canonicats de València, 1535-1740, f. 110v.

5 Ocupada hasta hacía sólo unas semanas por el difunto don Juan Roselló. ACV. Pahoner. J. Recopilación de especies sueltas perdidas pertenecientes a esta santa iglesia metropolitana y a sus preeminencias, vol. III, f. 420.

${ }^{6}$ Según escritura del notario Jacinto Leonart Esteve. ACV. Leg. 691, Llibre de possessions..., f. 115v.

${ }^{7}$ Sobre el tema, véanse entre otros los ya clásicos trabajos de Cereceda. F. 1944. «El litigio de los cabildos y su repercusión en las relaciones con Roma (1551-1556)». Razón y fe 130: 215-234; Marín Martínez. T. 1948. «Primeras repercusiones tridentinas: el litigio de los cabildos españoles. Su proceso en la diócesis de Calahorra», Hispania Sacra 1: 325-349; Mansilla. D. 1957. «Reacción del cabildo de Burgos ante las visitas y otros actos de jurisdicción intentados por sus obispos». Hispania Sacra X:
} 
de sus más vehementes manifestaciones, en Valencia, fue la rivalidad desatada a mediados del Seiscientos entre dignidades y canónigos. ${ }^{8}$ Estos últimos conformaban stricto sensu el capítulo metropolitano, del que estaban excluidas las dignidades, empeñadas en equipararse a los canónigos y compartir con ellos el gobierno de la iglesia mayor. ${ }^{9}$

Mezclado en tales lides, encontramos a comienzos de 1658 a don Ventura Ferrer. A sus poco más de treinta años gozaba de un gran predicamento entre los suyos. Había conseguido aglutinar a un grupo de jóvenes dignidades que, pertenecientes como él a conocidas dinastías valencianas, andaban dispuestas a batallar con el cabildo por el control de la Seo. Era el caso del deán don Francisco Fenollet ${ }^{10} \mathrm{y}$ los coadjutores del arcediano de Alzira, don Diego de Torres, ${ }^{11} \mathrm{y}$ del sacrista, don Jerónimo Vallterra, hijo del lloctinent del portant-veus de general governador de Valencia don Vicente Vallterra. ${ }^{12}$

Coincidiendo con la promoción a Sevilla del arzobispo fray Pedro de Urbina y la declaración de la sede vacante, los cuatro plantearon su órdago el 25 de junio de 1658, con motivo de la celebración en la Catedral de la solemne octava del Corpus Christi. A la hora de reservar el Santísimo Sacramento, según algunos testigos allí presentes, desafiaron a los canónigos tratando de usurparles algunas preeminencias a ellos reservadas.

«subieron asta el último escalón inmediato al altar major y, sin guardar lo acostumbrado, que es el arrodillarse de uno en otro desde la esquina del altar asta abaxo, por su orden de antigüedad, haciendo ala y un cuerpo y choro con los canónigos, ocuparon todos tan solamente la última grada de arriba, donde hizieron su choro aparte, arrodillados, dándole las espaldas a los canónigos. Y aunque algunos capitulares les instaron que

135-159; Goñi Gatzambide. J. 1975. «Los cabildos españoles y la confirmación del concilio de Trento». Annuarium Historiae Conciliorum 7: 425-458; y Domínguez Ortiz. A. 1985. Las clases privilegiadas en el Antiguo Régimen: 238ss. Madrid: Istmo.

${ }^{8}$ Callado Estela. E. 2012. «Dignidades contra canónigos en la catedral de Valencia durante el siglo XVII». Estudis 38: 117-138.

9 1582. Epitome sive compendium constitutionum sanctae metropolitanae Ecclesiae Valentinae: 8ss. Titulus II. De his quae spectant ad canonicos et capitulum. Valencia.

${ }^{10}$ Llamado el Menor, el Moderno o el Segundo, para diferenciarse de su tío, el también deán don Francisco Fenollet, del que fue coadjutor desde el 10 de noviembre de 1645, a la edad de diecinueve años. A la muerte de éste, le sucedería al frente del deanato de la Catedral, el 26 de febrero de 1657, tomando por coadjutor, en agosto de 1660, a don José de Cardona. Falleció el 30 de mayo de 1701. ACV. 691, Llibre de possessions..., ff. 121v - 122, 123v y 127v. Su testamento en ACV. Leg. 614:14.

${ }^{11}$ El 20 de noviembre de 1643, con dieciséis años, había ingresado en la Catedral como coadjutor del arcediano de Alzira don José Sanz, cuyo fallecimiento le llevaría hasta la titularidad de esta dignidad el 18 de mayo de 1665. Tuvo a su vez por coadjutor, desde 1668, a don Pascual Cardona. El 24 de febrero de 1682 murió. ACV. 691, Llibre de possessions..., ff. 129v, 133 y 141. Su testamento en ACV. Leg. 646: 6.

${ }^{12}$ Había sido el sacrista don Cristóbal Sanoguera quien lo vinculó a la sacristía como coadjutor, con tan sólo 17 años, el 25 de noviembre de 1643. ACV. 691, Llibre de possessions..., f. 113v.

Hispania Sacra, LXVI

133, enero-junio 2014, 109-131, ISSN: 0018-215X, doi: 10.3989/hs.2013.048 
guardasen la devida conformidad y orden, sin embargo persistieron en los mismo asta lo último de la función». ${ }^{13}$

Lo peor estaba por llegar, a juzgar por los testimonios conservados.

«Sucedió también que, habiéndose arrodillado el [canónigo] magister, a quien le toca esto por su ministerio, después de haver despejado el altar, en la misma grada, en la parte que va de la esquina del altar asta el retablo y la pared, uno de las dignidades que le tenía más cerca, echándose sobre él, le apretó sobremanera y molestó con indesencia, y entrando en el sagrario le dixo otro de las dignidades que, si a él fuera, le hubiera quemado las barbas y echado de allí a puntillazos». ${ }^{14}$

Concluida la ceremonia, el doctor don José Barberá, vicario general de la sede vacante,$^{15}$ decretó el arresto domiciliario de los alborotadores, so pena de quinientos ducados de sanción para cada uno de ellos en caso de abandonar sus hogares. Lo hizo Ferrer sin el menor escrúpulo. El chantre gritó a los nuncios de la curia eclesiástica que «no se tenía por arrestado, y con la misma galantería se salió a passear». Tampoco el coadjutor del arcediano de Alzira se avino al mandato, pues «se salió de casa sin parezer más asta el otro día». Don Jerónimo Vallterra estuvo ilocalizable toda la jornada. Sólo el deán Fenollet obedeció.

A la mañana siguiente, penúltimo día de la octava, corrió el rumor por la capital de que don Ventura asistiría a los oficios catedralicios, en compañía de los otros dos prófugos, para insistir en su pretensión, y que, «a instancias y convocasiones suyas, estaba la iglesia llena de muchos caballeros, sus parientes y amigos y de otro género de gente que nunca suele acudir a la iglesia; [y] que había muchas armas prevenidas; y entre los demás, algunas personas de mal ayre y peor reputación». ${ }^{16}$

Previendo posibles altercados, el vicario general solicitó el auxilio de la jurisdicción real para prender a las dignidades desobedientes. Mientras el asunto era consultado con las salas del Tribunal, Ferrer, Vallterra y Torres irrumpieron en la Seo tal y como habían anunciado. La excomunión lanzada sobre ellos por don José Barberá resultó fulminante. Sin embargo, fue la ausencia del canónigo magister lo que evitó la repetición de los incidentes de la anterior jornada.

No hubo tanta suerte el 27 de junio. Aún excomulgados, el chantre y los coadjutores desafiaron otra vez la autoridad del vicario general de la sede vacante.

${ }^{13}$ Archivo de la Corona de Aragón [=ACA]. Consejo de Aragón. Leg. 732, doc. 38 / 4.

14 Ídem.

${ }^{15}$ Canónigo desde el 20 de septiembre de 1645, ejercería como obispo auxiliar de la diócesis, con el título de Maronea, desde el 5 de septiembre de 1661. Guitarte Izquierdo. V. 1985. Obispos auxiliares en la historia del arzobispado de Valencia: 59-60. Castellón: Ayuntamiento de Castellón. Seis años después vincularía a su canonicato, en calidad de coadjutor, a un sobrino del mismo nombre. Falleció el 19 de agosto de 1675. ACV. 691, Llibre de possessions..., ff. 115v, 131v y 137.

${ }^{16}$ ACA. Consejo de Aragón. Leg. 732, doc. 38 / 4. 
Se personaron nuevamente en la iglesia mayor para cerrar la octava. Un par de alguaciles reales lograron sacarlos fuera del templo sin grandes problemas. Semejante contumacia, con todo, sirvió al doctor Barberá para apelar al Consejo de Aragón. «Estos caballeros - escribió- entienden que en la sede vacante no tienen superior». Ejemplo tan poco edificante, alertaba, «a de multiplicar las inobediencias en muchos de igual o inferior esfera por su calidad o por su orgullo». De ahí que «nunca, como hoy, a ssido tan preçisso çanjar la auctoridad para el castigo de los ecclesiásticos en esta tierra sircunstançiada con diferentes delictos de personajes que la inquietan y perturban...». ${ }^{17}$

Los hechos dieron la razón al vicario general cuando, pocos días después, el magister de la Seo era amenazado de muerte por don Ventura Ferrer, quien resentido con todo lo recientemente acontecido «entró en su casa maltractándole con palabras injuriosas». Sólo la mediación de un conocido de ambos evitó que corriera la sangre.

No dolieron prendas al virrey don Manuel de los Cobos, marqués de Camarasa, para condenar sin paliativos las demasías del chantre, tan impropias de un hombre de su calidad. Ya llegaría el momento de castigarle, si este era el caso. Por ahora, el noble comunicó a Felipe IV que obligaría a dignidades y canónigos a sellar la paz. Caso de no hacerlo, siempre quedaba el recurso del destierro, pues «no era nuevo en Valençia mandar vuestra majestad apartar de ella canónigos y dignidades quando su proceder se encuentra con el bien público». ${ }^{18}$

El Consejo de Aragón sancionó la determinación del marqués de Camarasa, a la que añadió, para tratar de garantizar su éxito, el alejamiento provisional del magister de su lugar en la Catedral y la prolongación del arresto domiciliario de las cuatro dignidades rebeldes, a las que se instó a solicitar la absolución ad cautelam de las censuras canónicas lanzadas por don José Barberá para normalizar su situación. ${ }^{19}$

Así las cosas, el 21 de julio un satisfecho don Manuel de los Cobos informaba al monarca del principio de acuerdo alcanzado por las partes, arruinado tan sólo cuatro días después a causa del nuevo altercado protagonizado en la Catedral por Ferrer y sus correligionarios. Estos rompieron el confinamiento decretado por la Corona para personarse en el templo y reclamar la presidencia del coro en mitad de los oficios divinos. Para ello, «convocaron mucha gente de

17 Ídem.

${ }^{18}$ ACA. Consejo de Aragón. Leg. 732, doc. 38 / 13 - 38 / 15. Los casos, motivados por diferentes causas, fueron numerosos a lo largo del siglo XVII. Callado Estela. E. 2003: 90ss.

${ }^{19}$ ACA. Consejo de Aragón. Leg. 732, doc. 38 / 17. 
los bandos cargados de pistolas y caravinas [y] les hicieron venir a la iglesia por mover ruido y matar dentro della a los que les contradixessen». ${ }^{20}$

Cuarenta y ocho horas más tarde, antes de iniciarse las celebraciones religiosas, el encontronazo volvía a producirse. Entró en el coro el chantre, tomó asiento y

«habiéndose seguido después don Balthasar de Blanes ${ }^{21}$ y otros canónigos, saludaron a su presidente canónigo. Subió don Balthasar a su coro, que es el de don Ventura, y al pasar por delante no se lebantó ni le hizo cortesía alguna, siendo assí que es stilo del coro levantarse canónigos y dignidades por donde ha de pasar el que entra de nuevo. Díjole don Balthasar: ¿Cómo no me haze la cortesía que se me debe?. Don Ventura respondió: ¡Yo defiendo las preeminencias de mi dignidad, y como presidente del coro no debo hazer otra!. Replicó don Balthasar que sabría obligarle a hacerla. Y añadió don Ventura que aquello no hera para allí. Don Balthasar replicó que allí y en qualquier parte, saliéndose del coro donde se quedó don Ventura hasta acabados los offiçios».22

Para entonces un par de nuncios del vicario general aguardaban a don Ventura en las puertas de la sacristía. Alertado por varios amigos, logró huir por una reja del altar mayor vestido con los hábitos de coro. Un coche de caballos dispuesto fuera le condujo hasta el domicilio de su cuñado don Félix Falcó. ${ }^{23}$ Allí fue detenido horas después.

Entretanto, don Jerónimo Vallterra protagonizaba «otro lance para perderse con el canónigo Caspe, ${ }^{24}$ el qual estaba acompañado de diez o doze escopetas para matar a don Gerónimo». Ferrer y Vallterra fueron confinados en unas dependencias del palacio arzobispal ocupadas habitualmente por la servidumbre de la mitra.

Aquella misma tarde irrumpían violentamente en casa del doctor Barberá los familiares de uno de los reos, don Vicente y su hijo don Carlos Vallterra, padre y hermano, respectivamente, del coadjutor del sacrista. La versión oficial de los hechos asegura que, sin empacho de la condición de ambos hombres, conocido

${ }^{20}$ Ibídem, docs. 38 / $19-38$ / 20.

${ }^{21}$ Nombrado canónigo de la Catedral el 29 de octubre de 1642, desde 1660 se le asignó por coadjutor al joven don Jerónimo Frígola. Falleció el 18 de septiembre de 1674. ACV. Leg. 691, Llibre de possessions..., ff. 112v, 127 y 137.

${ }^{22}$ ACA. Consejo de Aragón. Leg. 732, docs. 38 / 19 - 38 / 20.

${ }^{23}$ Jurado del cap $i$ casal en 1668 y Justicia criminal al año siguiente. Felipo Orts. A. 1996. Insaculación y élites de poder en la ciudad de Valencia:149. Valencia: Alfons el Magnànim.

${ }^{24}$ Eugenio de Caspe, coadjutor del canónigo don José Sanz desde el 15 de febrero de 1640, sustituiría a éste en la prebenda, una vez fallecido, el 18 de mayo de 1665 . No tardó en tomar por coadjutor al diácono Jaime Salt, prematuramente desaparecido poco antes de que Caspe encontrara la muerte, el 21 de junio de 1668. ACV. 691, Llibre de possessions..., ff. 109 y 130 - 130v. 
lloctinent del portant-veus de general governador el primero y juez de diezmos el segundo, ${ }^{25}$

«maltrataron al vicario general de palabras, hablándole con voces desconpuestas y votos a Christo sobre la prissión de don Gerónimo Vallterra, diçiéndole quien lo havía votado, lo havía votado mui mal y que a su hijo no le avían de tractar de aquella manera, añadiendo palabras tan pessadas que, por serlo, no han querido declararlas personas ecclesiásticas que se hallaron en otra pieza inmediata; y asseguran que llegaron a arrinconar al vicario general en una esquina del apossento donde estaban». ${ }^{26}$

Don José Barberá denunció al monarca el atropello perpetrado en su persona, sobre la que descansaba la primera autoridad de la Iglesia durante la sede vacante. ${ }^{27}$ Los canónigos cerraron filas en torno a él por medio de su portavoz don Gaspar Guerau de Arellano. ${ }^{28}$ Para éste, la intervención del doctor Barberá «sólo se dirige al zelo de la paz de esta Iglesia y sosiego de esta tierra, donde esparcidas ya algunas malas violencias, es el peligro harto considerable». Nada parecía poder detener en su ambición al grupo del chantre, añadía el canónigo, ni siquiera la autoridad del rey, «pues con haverse salido de las cárçeles amenazan terribilidades y amagan horrores contra los ministros de la jurisdición eclesiástica y otros...». ${ }^{29}$

Continuaron escuchándose por todas partes acusaciones muy similares contra las dignidades. Pero ninguna como la elevada al Consejo de Aragón a comienzos del mes de agosto de 1658, con don Ventura Ferrer y don Jerónimo Vallterra en el punto de mira.

${ }^{25}$ Desde 1661 pasaría a ejercer como asesor del portant-veus de general governador. Un lustro después actuaba como oidor de causas civiles de la Real Audiencia, cuya regencia ocupó a comienzos de 1681. Canet Aparisi. T. 1990. La Magistratura valenciana (siglo XVI-XVII): 178. Valencia: Universitat de València.

${ }^{26}$ ACA. Consejo de Aragón. Leg. 732, doc. 38 / 29.

${ }^{27}$ Ibídem, doc. 38 / 1.

${ }^{28}$ De la noble casa de Garcerán Guerau de Pinós era hijo de don Gaspar Guerau de Arellano y doña Flavia Pavessi y hermano, entre otros, de don Baltasar Guerau de Arellano, Maestre Racional de Valencia. Esquerdo. O. 2002. Nobiliario valenciano: II, 363-364. Valencia: Biblioteca Valenciana. A los diecisiete años se había incorporado al cabildo de la Catedral. En principio como coadjutor del doctor Martín Bellmont, su tío. Sin embargo, el inesperado fallecimiento de éste le llevó a ocupar el canonicato en propiedad el 12 de julio de 1643. Don Francisco Vives y Juan, desde 1656, don Pedro Martínez de la Raga, a partir de 1669, y su sobrino don Jerónimo Monsoriu y Castellví, desde 1701, le auxiliarían sucesivamente como coadjutores hasta su desaparición, el 10 de diciembre de este último año, recibiendo sepultura en el convento de Nuestra Señora de la Trinidad. ACV. 691, Llibre de possessions..., ff. 112v, 123, 133, 152 y 153v. De clara vocación política, ejerció durante años como síndico del estamento eclesiástico, embajador del Reino de Valencia y portavoz de sus reivindicaciones ante la Corona. Guía Marín. Ll. J. 1975. «Los estamentos valencianos y el duque de Montalto: los inicios de la reacción foral». Estudis 4: 129-146, y García Martínez. S. 1991: 182, 184, 190 y 196 - 199.

${ }^{29}$ ACA. Consejo de Aragón. Leg. 732, doc. 38 / 2.

Hispania Sacra, LXVI

133, enero-junio 2014, 109-131, ISSN: 0018-215X, doi: 10.3989/hs.2013.048 
«Estos dos caballeros son cabos de los bandos y los fomentan, como es notorio, ni se ordenan ni ay hombre que les aya visto el breviario en las manos. Don Ventura Ferrer es público que hizo matar un clérigo camino del lugar de Picassent a unos bandidos por una mujer. En su casa, se sirve de la mayor [hechi]sera del mundo, penitenciada por el Santo Officio y desterrada. Su proceder no es de ecclesiástico, assí en el vestir como en las grandes guedejas que lleva, que más parece rufián que no de Iglecia. Su trato es con gente facinerosa y de mala vida. Don Gerónimo Vallterra es aún peor que éste, porque como su padre es tiniente de governador y cavesa de los bandos y todos sus hermanos, va amenasando a todos que les matará si se le oponen. Su padre lo fomenta. Su hermano don Carlos viene con él a la iglesia, acompañándole con mucha gente de armas a que mueva ruydos y escándalos en la iglesia por ver si se le opondrá alguno. En fin..., adonde quiera que están inquietan, sino dígalo esta ciudad, dígalo el reyno y también el lugar de Bonete en Castilla, por lo qual anda ausente con bandosidad el hermano mayor don Jusepe. ${ }^{30}$ Díganlo, finalmente, los procesos fulminados contra todos ellos y la fama que tienen de facinerosos». ${ }^{31}$

Efectivamente, ambos clérigos eran miembros destacados del clan de los Vallterra, una de las bandositats que desde hacía décadas desangraba el Reino. ${ }^{32}$ Antiguos aliados de los Anglesola, don Vicente Vallterra, su numerosa prole, otros familiares y adláteres, habían mantenido durante años estrechos lazos con el Almirante de Aragón, don Francisco de Cardona, al que ahora, sin embargo, se hallaban enfrentados. ${ }^{33}$ Este último contaba con simpatizantes entre el clero de la Catedral de Valencia, como el influyente don Gaspar Guerau de Arellano. Todo lo cual pasaron por alto los canónigos al exigir a la Corona el destierro del chantre y el coadjutor del arcediano de Alzira.

«si vuestra magestad no pone su mano poderosa en sacar a todos estos del reyno, se perderá esta Santa Iglesia con lo que podrá suceder, porque cada día está a pique de haver muchas desdichas..., porque aquí no quieren conocer por superior al vicario general ni le obedesen en nada, y como están apoderados de la gente bandida les teme el vicario general». ${ }^{34}$

Por ahora, la corona se limitó a ofrecer al doctor Barberá algunos hombres armados para garantizar su integridad física al tiempo que ponía a su disposición los calabozos reales para la guardia y custodia de don Ventura Ferrer y don Jerónimo Vallterra. Los dos permanecieron aislados en las dependencias episcopales bajo la custodia de los nuncios de la curia eclesiástica. Estas prevenciones no impidieron que ambos convivieran juntos en la misma estancia con absoluta normalidad, organizando algún que otro sarao, con banquete y timba incluida.

${ }^{30}$ Don José Vallterra, uno de los miembros más activos del clan Vallterra, muy pronto ajusticiado por su largo historial delictivo, el 29 de diciembre de 1659. Guía Marín. L1. J. 2002: 311.

${ }^{31}$ ACA. Consejo de Aragón. Leg. 732, doc. 38 / 25.

32 García Martínez. S. 1991:177ss.

${ }_{33}$ Guía Marín. L1. J. 2002: 303 y 311.

${ }^{34}$ ACA. Consejo de Aragón. Leg. 732, doc. 38 / 25. 
Entre las visitas recibidas, la de don Carlos Vallterra, que en un descuido de los carceleros facilitó la huída de los reos. ${ }^{35}$

A mediados de agosto Felipe IV ordenaba a su lugarteniente general el esclarecimiento de estos sucesos. Asimismo hizo sentar de nuevo a dignidades y canónigos para que se reconciliaran definitivamente por las buenas o, de no avenirse a ello, por las malas.$^{36}$ No resultó este encargo sencillo para el Virrey, pese a sus esfuerzos durante los meses siguientes.

Las informaciones de los testigos apuntaron directamente a los Vallterra como instigadores de los incidentes. ${ }^{37}$ Mientras el joven don Carlos daba con sus huesos en la cárcel hasta nuevo aviso, su padre era apercibido para alejarse siete leguas de Valencia a la espera de instruírsele un proceso judicial a finales de año. ${ }^{38}$

Nuevos testimonios habrían de confirmar la culpabilidad del lloctinent de portant-veus de general governador a comienzos de $1659 .{ }^{39}$ Aun así, consideraron los jueces que el delito del mayor de los Vallterra «pareze que no es de residencia, por no haverle cometido don Vicente como ministro ni con pretexto ni color de offiçio, sino con el sentimiento que, como padre, le causó el ber a su hijo en puesto indeçente». La Corona, pues, prefirió renunciar a cualquier castigo. Únicamente, a través del marqués de Camarasa, reprendería su comportamiento, exigiendo firme promesa de conducirse en lo sucesivo más rectamente. ${ }^{40}$

Peor fortuna corrieron las negociaciones entre dignidades y canónigos, entorpecidas por las amenazas cruzadas entre cabecillas y valedores de cada grupo. Don Gaspar Guerau de Arellano fue afrentado públicamente por don Luis Milá y don Francisco Vallterra, yernos ambos de don Vicente Vallterra e «ynteresados en las diferençias entre canónigos y dignidades». Uno y otro pagarían su descompostura con el arresto decretado por el Virrey, quien aprovechó la ocasión para reconocer ante Felipe IV su incapacidad en el ajustamiento de la paz catedralicia,

«Yo he discurrido... con unos y otros varias vezes, experimentando lo mismo, con que reconociendo la imposibilidad total de conseguirse la materia... me ha parecido más conveniente no entrar en ella». ${ }^{41}$

${ }^{35}$ Ibídem, doc. 59 / 5.

${ }^{36}$ Ibídem, doc. 38 / 26.

${ }^{37}$ Ibídem, docs. 38 / 6 y 38 / $45-38$ / 48.

${ }^{38}$ ACA. Consejo de Aragón. Leg. 664, doc. 68 / 2.

${ }^{39}$ Ibídem, doc. 66 / 5.

${ }^{40} \mathrm{Ibídem}$, doc. 60 / 4.

${ }^{41}$ ACA. Consejo de Aragón. Leg. 732, doc. 38 / 28. La arribada de este prelado y los inicios de su pontificado en Ballester. J. B. 1672. Identidad de la imagen del Santo Christo de San Salvador de Valencia con la sacrosanta imagen de Christo de la ciudad de Berito, en la Tierra Santa. Con el 
Poco más conseguirá el nuevo arzobispo de Valencia don Martín López de Hontiveros, llegado a la diócesis en mayo de 1659 con instrucciones precisas de la Corona para reconducir la situación. ${ }^{42}$ El vicecanciller del Consejo de Aragón hubo de llamar a Madrid a las partes enfrentadas, representadas por don Ventura Ferrer y don Gaspar Guerau de Arellano, para aproximar posturas. ${ }^{43}$ Pero nada impidió que el litigio siguiera candente durante la nueva década. Así estaba al menos cuando a uno de sus principales actores, el chantre, le sorprendió la muerte dejando a los suyos sin liderazgo.

Fue el martes 1 de marzo de 1661. A las doce y media del mediodía Ferrer regresaba a casa, muy próxima a la calle de la Morera Vera, después de haber pasado casi toda la mañana en la Catedral, donde había asistido a los oficios matutinos celebrados para impetrar el fin de la sequía que desde hacía meses padecía Valencia ${ }^{44} \mathrm{~A}$ la altura del Trinquete de Caballeros se topó con un par de desconocidos, que sin mediar palabra le descerrajaron dos carabinazos en el vientre antes de darse a la fuga. ${ }^{45}$

El cuerpo sin vida de don Ventura cayó abatido en medio de un gran charco de sangre. En torno a él, empezaron a arremolinarse decenas de transeúntes, vecinos y familiares de la víctima. Alertados por los gritos y sollozos, un grupo de alguaciles reales se personó en el lugar de los hechos. La tensión a continuación vivida, mientras el cadáver era levantado, obligó a los ministros a practicar varios arrestos entre los parientes y amigos de don Ventura allí congregados.

La noticia sorprendió al Virrey marqués de Camarasa en una reunión que hubo de suspender para desplazarse a toda prisa desde el Palacio Real hasta el lugar de los hechos y conocer in situ lo ocurrido. De vuelta a su residencia, convocó con carácter de urgencia a la sala criminal de la Real Audiencia, a la que ordenó la inmediata liberación de los arrestados así como la puesta en marcha de una investigación que aclarara los detalles del crimen. El noble quiso informar personalmente de lo sucedido al vicecanciller del Consejo de Aragón

cathálogo de las vidas de todos los obispos y arçobispos de Valencia, desde san Eugenio y tiempos de los apóstoles hasta oy, y con un resumen de varios sucesos pertenecientes a Valencia en 16 siglos: 628630. Valencia: J. Villagrasa.

${ }^{42}$ ACA. Consejo de Aragón. Leg. 744, doc. 91 / 1.

${ }^{43}$ ACA. Consejo de Aragón. Leg. 745, doc. 34.

${ }^{44}$ Biblioteca Universitaria de Valencia [=BUV]. Ms.158, Alegre. D. Parte segunda de la Historia de las cosas más notables deste real convento de Predicadores de Valencia 1660-1672: s.f.

${ }^{45}$ De las crónicas coetáneas, sólo la de O. Esquerdo, y de manera muy lacónica, se hace eco del suceso: «En 1 de março 1661 entre dose y una de mediodía mataron en dos escopetasos al Tri[n]quete de Cavalleros a don Ventura Ferrer, cabiscol de la Seo de Valencia». Archivo del Real Convento de Predicadores de Valencia [=ARCPV]. Ms. 32, Esquerdo. O. Memoria valenciana, f. 75. Puede consultarse la edición moderna de este relato en Callado Estela. E. y Esponera Cerdán. A. 2004. Memoria escrita, historia viva. Dos dietarios valencianos del Seiscientos: 91-178. Valencia: Ayuntamiento de Valencia. 
don Cristóbal Crespí de Valldaura, al que escribió lo siguiente antes de darle el pésame por la muerte de su sobrino.

«allándose esta ciudad ocupada en sus rogativas por agua y en la quietud que no se ha visto jamás en este tiempo, oy martes, a mediodía, yendo don Bentura Ferrer, dignidad desta santa iglesia y de los calificados de aquí, solo y a pie para su casa, que está cerca la calle de la Morera Vera, le mataron de dos caravinaços, sin que tuviese tiempo ninguno para mirar por su alma y en fragante delito. No habiéndose allado rastro alguno de los agresores, ni de cómo sucedió, los ministros de justicia, a prevención, arrestaron en sus casas a algunos de sus parientes». ${ }^{46}$

Al día siguiente se iniciaba la investigación ordenada por la lugartenencia general, a la que desde el primer momento, y prácticamente hasta el final, faltó colaboración por parte de testigos y familiares de la víctima, silenciados por miedo o afán de venganza. Ni siquiera el primer bando ofreciendo una recompensa de doscientas libras por cualquier información arrojó ninguna luz al respecto de los agresores. ${ }^{47}$

No consiguió más el arzobispo don Martín López de Hontiveros con sus gestiones entre los eclesiásticos en las cuarenta y ocho horas siguientes al crimen. De ahí la importancia de testimonios anónimos como el recibido por el marqués de Camarasa la noche del 5 de marzo por parte de un confidente que identificado como «su menor y más humilde capellán». El misterioso clérigo tendría respuestas para todo. La muerte de Ferrer respondía a su supuesto galanteo con la doncella doña Isabel de Cardona; y el autor intelectual de la misma, el padre ultrajado, el mismísimo Almirante de Aragón.

«bien me parece estará advertido vuestra excelencia ser el Almirante y su ijo autor de la tragedia [que] experimentó el chantre de esta santa iglesia el martes de Carnestolendas por siertas sospechas de sierto galanteo». ${ }^{48}$

Don Francisco de Cardona, pues, habría encargado tan delicado asunto a su mano derecha. Era ésta don Vicente Adell, enfrentado durante años al bando de Leandro Escales ${ }^{49}$ y, desde la década de los cincuenta, principal sicario del Almirante, a cuenta de cuyos trabajos padeció sucesivos destierros. ${ }^{50}$ Adell habría recurrido a don Jaime de Próxita para contratar a varios esbirros que eliminaran al chantre de la Catedral de Valencia y se deshicieran después de todo aquel que pudiera querer vengar al difunto. Esta era la versión completa de los hechos:

\footnotetext{
${ }^{46}$ ACA. Consejo de Aragón. Leg. 685, doc. 59 / 8.

${ }^{47}$ Archivo del Reino de Valencia [=ARV]. Real Cancillería. Curiae Lugartenenciae, 1392, s. f.

48 ACA. Consejo de Aragón. Leg. 685, doc. 59 / 11.

${ }^{49}$ Casey. J. 1983: 219-222.

${ }^{50}$ Guía Marín. Ll. J. 2002: 298.
} 
«se valió de don Jaime de Próxita. Y éste les respondió era mejor medio, por lo demás amigos, mosén Estevan Alver. Con que, llamándole, consertaron entrase dos hombres en Valençia, como en efeto les entró. Del uno, no se sabe el nombre; el otro se llama Joan Biscart o Bisquert, hombre [que] a vivido en trabaxo pero [que] ya no era dedudor de la justiçia. Éstos..., sin más interez que la quietud de muchos y guardar la vida, se la quitaron el día [que] he dicho. Lo que más para el servicio de Dios en esta ocasión es lo echo no tiene remedio, dexar de ser que dexen o que desistan estos obstinados cavalleros de la resolución [que] an tomado de aser matar a don Luis Ferrer, al doctor Laquaga y a don Jerónimo Vallterra, por deudos, amigos y valedores. La execusión de esta resoluçión la an tomado por su qüienta. Los alrededores tienen por su casa, como don Visente Adell, mosén Sánchiz, Valcarera, mosén Noguera, Christóval Marco, Ferrando Gaso y Francisco Martorel; aviendo sido todos cónplises y espías en la muerte del desdichado cavallero, como algunos de los referidos, con capa de amistad, aver echo venta de su sangre la noche del día [que] la derramó, y la siguiente rondaron las puertas de los dichos don Luis y del doctor Laquaga». ${ }^{51}$

Desde luego, era un secreto a voces en toda la ciudad que detrás del asesinato de Ferrer no se hallaba sino don Francisco de Cardona. Había faltado tiempo al noble para sentenciar a muerte al galanteador de su hija, por lo demás hechura de sus enemigos los Vallterra, con quienes teóricamente acababa de hacer las paces por imposición de la Corona.$^{52}$ Sin embargo, ni una sola prueba fehaciente de la implicación del Almirante de Aragón obraba en poder de la Lugartenencia General del Reino, concluida la primera semana de investigación. De ello se dolió el Marqués de Camarasa ante el Vicecanciller del Consejo de Aragón, lamentando el descrédito de la justicia real «por no hallar cómo satisfacerse con demostración de castigo igual por ser el delinqüente principal el que se supone». Adell, por el contrario, amigo de bandos y bandidos desde su más temprana mocedad, estaba encarcelado desde el pasado día 7 para impedir que «se encienda más este fuego y no pueda estinguirse». ${ }^{53}$

A falta de testigos, la Real Audiencia trató de demostrar la participación de don Francisco de Cardona en el crimen, partiendo de los vínculos que le unían con su hombre de confianza. Primero, con la visita de éste a aquél durante el día de autos, y luego, con la correspondencia requisada al segundo, casi una decena de cartas, rubricadas de puño y letra del Almirante, sobre los negocios turbios entre ambos y con algunos nombres que circulaban de boca en boca como ejecutores del asesinato. ${ }^{54}$ Las informaciones extrajudiciales que salpicaban al noble continuaron acumulándose, hasta darse por cierto que los agresores del chantre habrían salido de su casa para cometer el crimen. Así lo creyó al menos el virrey el 15 de marzo.

\footnotetext{
${ }^{51}$ ACA. Consejo de Aragón. Leg. 685, doc. 59 / 11.

52 Guía Marín. Ll. J. 2003: 92.

53 ACA. Consejo de Aragón. Leg. 685, doc. 58 / 9.

${ }^{54}$ Exactamente siete misivas, fechadas entre el 22 de abril y el 23 de noviembre de 1660 . Ibídem, docs. $59 / 2-59 / 8$.
} 
«Joan Bisquert pareze está immune del delito... Hoy las noticias que parezen más seguras son que fueron los agressores N. Diana, de Xàtiva, remitido para este efecto por don Jaime de Próxita, y mosén Domingo del Grao, que estaban en casa del Almirante. Y al tiempo que salió don Bentura de la iglesia mayor, le siguió... una mujer que suponen es madre de mosén Ciurana,${ }^{55}$ uno de los guiados. Y al llegar a Sant Estevan, que era su camino ordinario, por no pasar por casa del Almirante, adonde llegó a avisar la mujer y salieron los homicidas a executar la desdicha, llegando primero al puesto donde, afectadamente, se juntaron a hablar como de negocio, y al pasar don Ventura le tiraron». ${ }^{56}$

Una semana más tarde el Almirante de Aragón obligaba a su hija doña Isabel de Cardona a ingresar en el convento de Nuestra Señora de Gracia, en la Zaidia. ${ }^{57}$ El Marqués de Camarasa volvió a escribir entonces al Vicecanciller del Consejo de Aragón insistiendo en las dificultades para sentar en el banquillo a los culpables de la muerte de don Ventura Ferrer.

«En lo extrajudicial se confirman aquellas noticias, pero judicialmente no se ha escrito cosa alguna, pues aunque se sepa algo no habrá quién lo testifique por el riesgo a que se pone tan experimentado en esta ciudad; y la justicia ha apremiado los vecinos verosímilmente informados, mas no tiene noticias ciertas ni bastante provadas para pasar a maiores apremios». ${ }^{58}$

En nada contribuyó al esclarecimiento de los hechos la intervención del Santo Oficio, al que apeló don Vicente Adell, pues era familiar del Tribunal. En Valencia, al igual que en muchas otras partes,${ }^{59}$ eran frecuentes los desencuentros entre ministros reales e inquisidores a resultas de las siempre controvertidas familiaturas, cuyo número, jurisdicción y comportamiento habían sido regulados por sucesivas concordias sin lograr acabar con los excesos cometidos por la inmunidad que amparaba a estos colaboradores de la Inquisición, a la que correspondía juzgar cualquier falta civil o criminal de la que pudieran ser acusados. ${ }^{60}$ Sin ir más lejos, la competencia suscitada años atrás por los crímenes

\footnotetext{
${ }^{55}$ Podría tratarse de mosén Pedro Siurana, cuya prisión en los calabozos reales había desatado a comienzos de 1660 un sonado contencioso con la jurisdicción eclesiástica. Callado Estela. E. 2003: 82-88.

${ }^{56}$ ACA. Consejo de Aragón. Leg. 685, doc. 59 / 1.

${ }^{57}$ En él profesaría como religiosa, poco tiempo después, y allí permanecería al menos hasta 1668. Callado Estela. E. 2003: 99-100.

58 ACA. Consejo de Aragón. Leg. 685, doc. 59 / 11.

${ }^{59}$ Pérez Villanueva. J. 2000. «La Inquisición y los otros poderes. Problemas de competencia, sentencias y arbitrios», en Pérez Villanueva, J., y Escandell Bonet, B. (Dirs.): Historia de la Inquisición en España y América III. Temas y problemas: 187ss. Madrid: BAC.

${ }^{60}$ Sobre la problemática de las familiaturas en el ámbito valenciano véase García Cárcel, $\mathrm{R}$. 1980. Herejía y sociedad en el siglo XVI. La Inquisición en Valencia 1530 - 1609: 140-155. Barcelona: Península, y Haliczer. S. 1993. Inquisición y sociedad en el reino de Valencia (1478-1834): 241-327. Valencia: Alfons el Magnànim.
}

Hispania Sacra, LXVI

133, enero-junio 2014, 109-131, ISSN: 0018-215X, doi: 10.3989/hs.2013.048 
atribuidos a don Bernardo Adell, padre de don Vicente y también familiar del Santo Oficio como él, se había zanjado con la pérdida de su aforamiento. ${ }^{61}$

Ahora se trataba de otro Adell, cuya entrega reclamó por dos veces a la Real Audiencia, entre el 16 y el 18 de marzo, el inquisidor de Valencia don Pedro Ochogavia. En ambas ocasiones, la solicitud fue desestimada, apelando a la potestad económica, que autorizaba a los oficiales de la Corona a proceder por la vía extrajudicial contra algunos malhechores - fuera cual fuera su condición- cuando las circunstancias así lo recomendasen..$^{62} \mathrm{El}$ empleo de este recurso por la justicia real, en su acoso contra la delincuencia, no era raro en Valencia, pese a los recelos de los estamentos del Reino o la propia Iglesia. ${ }^{63}$ De ellos era partícipe el Tribunal local del Santo Oficio cuando protestó formalmente contra el encierro de don Vicente Adell.

«con los súbditos de este tribunal nunca se ha obrado por este camino, pues en ningún tiempo le han faltado autoridad y jurisdicción para castigarlos condignamente por graves que sean sus delictos; y que assí no parece justo se quiera oy introducir esta novedad tan perjudicial a la jurisdicción del Santo Oficio y a todos sus ministros». ${ }^{64}$

El 1 de abril de 1661, por fin, se debatían en el pleno del Consejo de Aragón los acontecimientos ocurridos en Valencia durante el último mes. El vicecanciller don Cristóbal Crespí se abstuvo de las deliberaciones, dados los vínculos de sangre que le unían a sus principales protagonistas, no sólo al difunto chantre de la Catedral, sino también al presunto inductor de su asesinato, el Almirante de Aragón, del que también era pariente en cuarto grado. No participaron tampoco en la sesión don Francisco Palafox, marqués de Ariza y cuñado de don Francisco de Cardona ${ }^{65}$ ni don Vicente Moscoso, abogado fiscal del Consejo ${ }^{66}$ «a quien por lo pasado tiene recusado».

El asunto, por tanto, quedó en manos de los regentes don Pedro Villacampa, don Jorge de Castellví, don José Romeu y el conde de Robres. Tras estudiar las informaciones remitidas por el marqués de Camarasa, los cuatro dieron por sentada ante Felipe IV la responsabilidad del Almirante de Aragón y su compinche don Vicente Adell, dignos ambos de un escarmiento que, aún así, era desestimado en el caso del primero, cuyo honor andaba en juego.

\footnotetext{
${ }^{61}$ Guía Marín. Ll. J. 2002: 298.

${ }^{62}$ ACA. Consejo de Aragón. Leg. 685, doc. 59 / 21.

${ }^{63}$ García Martínez, S. 1991: 38.

${ }^{64}$ ACA. Consejo de Aragón. Leg. 685, doc. 59 / 24.

${ }^{65}$ Arrieta. J. 1994. El Consejo Supremo de Aragón (1494-1707): 614. Zaragoza: Fernando el Católico.

${ }^{66}$ Ibídem, p. 619.
} 
«aunque por las cartas que el Almirante escribió desde esta corte a don Vicente Adell, se colige quan mezclado está el Almirante en la correspondencia de gente inquieta y perturbadora de la paz pública, y que por esta causa se podría ussar con él de la potestad económica, sacándole del reyno sin processo, como otras vezes se ha platicado con él y con otros caballeros de mucha calidad, y aunque se entiende que mientras éste... estuviere en el reyno no ha de haver quietud en él, todavía repara el Consejo que podría tener grande inconveniente esta resolución en la ocasión presente, por ser el motivo principal del delito que se ha cometido en la muerte de don Ventura Ferrer, según dice el virrey, el galanteo de la hija del Almirante, a quien podrá resultar el descrédito y desdoro de su casa que se deja considerar, que aunque allí sea público, pero el día que la justiçia llegue a hazer esta demostraçión, se califica más la voz que se ha esparçido... Y assí, pareze al Consejo se escriva al virrey se prozeda en la materia... sin hazer novedad con el Almirante». ${ }^{67}$

Mucho menos benevolentes se mostraron los regentes con Adell, refrendando los procedimientos contra él instruidos por la Real Audiencia que, en ningún caso, debía entregarlo al Santo Oficio, sino probar su culpa y castigarlo como correspondía a un individuo de su calaña,

«porque ha sido toda su vida de los prinçipales fomentadores de bandos de aquel reyno en compañía de su padre don Sevastián Adell, a quien por la Inquisición mandó vuestra magestad en años passados quitaran la familiatura, y antes deviera el Tribunal de la Inquisiçión hazer lo mismo con el hijo en lugar de pretender repetirle de la jurisdicçión real». ${ }^{6}$

En este sentido actuó el Virrey de Valencia las semanas siguientes, encarcelando a los colaboradores del controvertido familiar de la Inquisición en la muerte violenta del chantre. Particularmente don Jaime de Próxita que, después de procurar los matones para perpetrar el crimen, había participado con su hermano, el dominico fray Constantino, en el asesinato de don Eugenio Anguerot, opuesto al casamiento de su hermana menor con un tercer Próxita, de nombre don Bernardo, protegidos todos del Almirante de Aragón. Puesto que nada podía hacerse con este último, opinaba el marqués de Camarasa que don Vicente Adell y don Jaime Próxita pagaran sus culpas hasta las últimas consecuencias, como informó a la corte el 12 de abril:

«el castigo podría hacerse con don Vicente Adell y con don Jayme, que pareçe cooperaron en el [crimen] y no tienen la disculpa de la causal por no tocarles, tomando en don Jayme por motivo la muerte de don Eugenio y haver en éste, como en el otro, la mala calidad; pues tampoco es buena la de don Jayme y es íntimo del Almirante y después que vino a Valençia afiançado, antes de entrar en la cárçel, me diçen a passeado con él públicamente lado por lado en su coche, acreditando assí lo que se dice y con nota de los que lo saben, que no son pocos; y de tener en Valençia el Almirante estos dos consejeros, aunque estén

\footnotetext{
${ }^{67}$ Guía Marín. L1. J. 2003: 102.

${ }^{68}$ ACA. Consejo de Aragón. Leg. 585, doc. 20 / 1.
}

Hispania Sacra, LXVI

133, enero-junio 2014, 109-131, ISSN: 0018-215X, doi: 10.3989/hs.2013.048 
en la cárcel, pareçe pueden seguirse algunos malos efetos, que se evitarán sacándolos del reyno y enviándolos a los presidios que parecieren más a propósito». ${ }^{69}$

El Consejo de Aragón aprobó la propuesta del lugarteniente general en el caso de Adell, no así en el de Próxita, cuya complicidad en los hechos investigados no estaba todavía probada del todo. Felipe IV hizo suyo este parecer el 30 de junio, ordenando al marqués de Camarasa que, en virtud de la potestad económica, preparara el destierro de don Vicente y su confinamiento en cualquiera de los presidios que poseía la Monarquía. La causa de don Jaime, por el contrario, debería atenerse a la vía judicial ordinaria. ${ }^{70}$

Así las cosas, el Consejo de la Inquisición asumió inesperadamente la defensa de Adell. Una decena de casos similares, ocurridos en los últimos cuarenta años, fueron esgrimidos para legitimar sus reivindicaciones. No se cuestionaba la potestad económica en manos de la Corona y la gravedad de los delitos de bandos objeto de condena, sino el modo desacostumbrado de proceder por parte de la Real Audiencia contra un familiar imputado por esta causa, «con quienes siempre ha procedido el Tribunal de la Inquisición por sí en lo jurídico, por no allarse exceptuados en las concordias; y en lo económico, executando las órdenes de vuestra magestad». ${ }^{71}$

Esta vez el Santo Oficio había sido apartado del caso sin explicaciones, mientras se encarcelaba irregularmente en los calabozos reales a uno de los suyos cuya avanzada edad, «de más de setenta y cinco años», en absoluto casaba con «aquel ardor que suele ocasionar estos delitos, y puede ser que se le imputen por personas interesadas». Flaco favor hacía este ejemplar a la reputación de la Inquisición local. Muchos de sus familiares, a la vista del trato recibido por don Vicente, «se han inquietado y desconsolado, de manera que van haciendo diligençias para dejar los títulos». El problema no era baladí si se tenía en cuenta la drástica reducción últimamente experimentada por las familiaturas en el ámbito valenciano, con más de cuatrocientas localidades sin su presencia y la herejía campando por ellas... ${ }^{72}$

Los lamentos de la Inquisición fueron silenciados por el Consejo de Aragón apelando al estado excepcional del Reino de Valencia, corroído por las parcialidades en las que militaban muchos súbditos del Santo Oficio, como se expuso al monarca:

${ }^{69}$ Ibídem, doc. 20 / 5 .

70 Ibídem, s. d.

${ }^{71}$ ACA. Consejo de Aragón. Leg. 685, docs. 59 / 14 - 59 / 20.

72 Diez años atrás había en el distrito del Tribunal de Valencia trescientos ochenta y nueve familiares, ciento once de ellos en la capital. A finales de siglo su número se había visto reducido a tan sólo ciento sesenta y dos, veintinueve de los cuales estaban domiciliados en la primera ciudad del reino. Haliczer. S. 1993: 248-249. 
«En el reyno de Valencia... se han encendido los bandos y multiplicádose los delitos de algún tiempo a esta parte con el exceso que a vuestra magestad es notorio. Y siendo justo a un tan grave daño aplicar grande remedio, se ha procurado por todas partes, reconoziendo que algunos de los culpados eran familiares del Santo Oficio que buscan esta exempçión sólo para poder delinquir». ${ }^{73}$

Era el caso, sin duda, de don Vicente Adell, a cuyo abultado historial delictivo se sumaba el atroz asesinato de don Ventura Ferrer. Sus crímenes merecían un escarmiento que el Santo Oficio no estaba en condiciones de garantizar, por mucho que, en anteriores ocasiones, la Corona hubiera ejercido a través de él la potestad económica, que reclamaban ahora los inquisidores. La Junta de Competencias, creada en 1626 para resolver los conflictos de jurisdicción entre las diversas instituciones de la Monarquía ${ }^{74}$ sería finalmente quien dilucidara este pleito por deseo expreso de Felipe IV. ${ }^{75}$

El virrey marqués de Camarasa, entretanto, insistió el 11 de octubre en la necesidad de punir a los demás involucrados en el asesinato del chantre, con don Jaime Próxita a la cabeza, «por lo notoria que es su mala calidad y que obró más en la muerte de don Ventura Ferrer que don Vicente Adell». Acababa de conocerse que este hombre había mandado eliminar a los autores materiales del crimen, Gaspar Diana y mosén Domingo del Grao, para impedir que pudieran implicarle. El primero fue muerto de varios pistoletazos propinados en Xàtiva por su hermano, el dominico fray Constantino de Próxita. Del segundo se desconocía su paradero, temiéndose lo peor.

La Real Audiencia continuaba tratando de probar la culpa de don Jaime en todas estas fechorías, aunque como el lugarteniente general sospechaba, «no será posible verificarle delito alguno, por ser hombre muy cauto y haverlos cometido con maña». ${ }^{76}$ En cualquiera de los casos, el marqués de Camarasa procuraría prolongar su encierro sine die hasta conseguir indicios judiciales en su contra. ${ }^{77}$

Para entonces, el enésimo enfrentamiento del Almirante de Aragón con los Vallterra, entre finales de año y comienzos de $1662,{ }^{78}$ uniría la suerte de esta causa al destino reservado a los dos bandos. En el mes de abril Felipe IV autorizó al virrey a proceder contra ambos «para arrancar de rraíz esta semilla de viçios y evitar tantos homiçidios, escándalos y pecados públicos»; contaría para ello con la colaboración del arzobispo don Martín López de Hontiveros, dado

\footnotetext{
${ }^{73}$ ACA. Consejo de Aragón. Leg. 685, doc. 59 / 12.

${ }^{74}$ Pérez Villanueva. J. 2000: 189.

${ }^{75}$ ACA. Consejo de Aragón. Leg. 685, doc. 59 / 13.

${ }^{76}$ ACA. Consejo de Aragón. Leg. 585, doc. 6.

${ }^{77}$ Ibídem, doc. 20 / 4.

${ }^{78}$ Guía Marín. Ll. J. 2002: 92.
} 
el elevado número de eclesiásticos implicados. ${ }^{79}$ Ninguna de las facciones y su entramado estuvieron a salvo de las acciones por la Lugartenencia General. No lo estuvieron los íntimos de don Francisco de Cardona, encabezados por él mismo, don Vicente Adell, el canónigo don Gaspar Guerau de Arellano y varios clérigos más, como mosén Valcanada o Valcarera ${ }^{80}$ y mosén Navarro. Tampoco lo estuvo el clan Vallterra, representado por don Jerónimo, don José, don Francisco y don Luis Milá, hijo, nieto y yernos, respectivamente, del patriarca don Vicente, ni sus más íntimos deudos, especialmente don Jerónimo Brizuela, pariente del vicecanciller del Consejo de Aragón, el canónigo don Jimeno Pérez Garrigues $^{81}$ y los beneficiados mosén Millá y mosén Esteso. ${ }^{82}$

Una vez más el Almirante de Aragón no rendiría cuentas por ordenar el asesinato de don Ventura Ferrer. Su condición le libró nuevamente de la prisión y el destierro que hubieron de padecer la mayoría de los citados. Sólo fue llamado a la corte, donde permanecería hasta el final de sus días. ${ }^{83}$

Peor lo tuvo don Vicente Adell, cuyos años y achaques no bastaron para impedir su confinamiento en Tortosa a mediados de julio de $1662 .{ }^{84}$ Poco después la Junta de Competencias se inhibía de su caso, devolviéndolo a los cauces ordinarios, y por tanto al acuerdo entre el Consejo de Aragón y la Inquisición. ${ }^{85}$ Los empeños de ésta operados a partir de entonces para traer a su familiar de vuelta a casa fueron rechazados. De ello hicieron responsable los inquisidores a don Cristóbal Crespí, «todo ha sido por dirección del vicecanciller por la muerte

${ }^{79}$ La cooperación de la mitra con la Lugartenencia General en este particular mereció las airadas críticas de algunos sectores del clero valentino, preocupados por el perjuicio acarreado para la inmunidad de la Iglesia. Según éstos, hasta «als mateixos juches y ministres paregué mal que consentís lo señor arquebisbe, perquè fonch posar la ynmunitat eclesiàtica en mà y jurisdicció del bras real». Aierdi. J. 1999. Dietari. Notícies de València i son regne, de 1661 a 1664 i de 1667 a 1679. A cura de V. J. Escartí: 223. Barcelona: Barcino. Protestas como estas obligaron al prelado a solicitar el amparo del Consejo de Aragón a quien pidió «se diese recado al señor nuncio para enterarle como conviene que no se alteren estas penas por causa del bien público, que pues yo me he determinado a este expediente señal es que estoi cierto que lo merezen, aunque las probanzas, por el achaque desta tierra, no están planas». ACA. Consejo de Aragón. Leg. 755, doc. 19 / 1. Véase en todo caso Callado Estela. E. 2003: 89 ss.

${ }^{80}$ Sabemos por el arzobispo de Valencia que éste «salió desterrado a Orán por quatro o más años, y después del arçobispado, aunque contra él no hay escrito ni probado cosa que importe, porque no es posible probarse. Ha aceptado la sentencia y juzgo que la cumplirá, que será grande servicio de Dios y quietud desta tierra el que éste y los demás estén fuera della». ACA. Consejo de Aragón. Leg. 755, doc. $19 / 1$.

${ }^{81}$ El 2 de marzo de 1645 había pasado a formar parte del clero de la Catedral de Valencia como coadjutor de su tío don Jimeno Pérez Argent de Calatayud. Tras el fallecimiento de éste, le sustituyó al frente del canonicato el 7 de enero de 1662. Una década más tarde, con fecha 16 de junio, festividad del Corpus Christi, fallecería. ACV. 691, Llibre de possessions..., ff. 115, 118 y 135v.

${ }^{82}$ ACA. Consejo de Aragón. Leg. 685, doc. 59 / 41.

${ }^{83}$ Guía Marín. Ll. 2002: 314.

${ }^{84}$ ACA. Consejo de Aragón. Leg. 685, doc. 59 / 35.

${ }^{85}$ Ibídem, doc. 59 / 32. 
de don Ventura, su sobrino». El Consejo de Aragón desmintió tal extremo con el ejemplo de don Jerónimo Brizuela, cuyo parentesco con Crespí no le había librado de pasar una buena temporada fuera de la Península. Más valía al Santo Oficio dejar tantas suspicacias y tomar como modelo la mitra valentina en su incondicional colaboración con la justicia real... ${ }^{86}$

El levantamiento del exilio de los represaliados por el marqués de Camarasa se produciría de manera escalonada desde comienzos de $1663 .{ }^{87}$ Por motivos humanitarios algunos regresaron antes. Uno de ellos fue Don Jerónimo Vallterra, viejo amigo del difunto chantre, elevado hacia poco a la dignidad de sacrista de la Seo por fallecimiento de su titular. ${ }^{88}$ Desterrado en Villena apenas posesionado de su nueva prebenda, cayó gravemente enfermo ${ }^{89}$ Trasladado hasta Valencia, murió el 10 de febrero, a los treinta y siete años. ${ }^{90}$ También el cabecilla de la facción catedralicia opuesta a la liderada por don Ventura Ferrer alegó problemas de salud para volver a la capital. Nos referimos al canónigo don Gaspar Guerau de Arellano, quien permutó su extrañamiento por un arresto domiciliario con el aval del Consejo de Aragón..$^{91}$ A don Vicente Adell, sin embargo, no le sirvieron vejez y dolencias para acortar su condena. Todavía en la Nochebuena de 1663 esperaba noticias sobre su retorno a Valencia mientras se le escapaban sus últimos años de vida. ${ }^{92}$

De los demás implicados en el asesinato del chantre todavía no penados parece que don Jaime Próxita logró eludir a la justicia. Su hermano fray Constantino, tras protagonizar un ajuste de cuentas en plena capital, junto al convento de la Merced, sí fue encarcelado. Pasarían varios meses todavía hasta que, el 3 de abril de 1664, junto a otros veinticinco hombres, en su mayoría clérigos como él, embarcaran con destino al norte de África. ${ }^{93}$ De allí regresaron antes de tiempo, para cumplir otro exilio en Roma y Alcalá de Henares. A comienzos de 1669, y con el respaldo de las autoridades dominicanas, el

${ }^{86}$ Ibídem, doc. 59 / 38.

${ }^{87}$ Guía Marín. L1. J. 2003: p. 93.

${ }^{88}$ Concretamente el 2 de febrero de 1662. ACV. 691, Llibre de possessions..., f. 128. «Y en el mismo día, a suplicación suya, dispensando la constitución de 17 de julio 1604, en que se dispuso el orden de sentarse en el choro los dignidades y canónigos, le concedió el cabildo se pudiese sentar en la quarta silla del choro del chantre durante la voluntad del cabildo». ACV. Pahoner: III, f. 200.

${ }^{89}$ Mosén Joaquín Aierdi anotaría en las páginas de su dietario como este clérigo «caigué mal en Villena, estant desterrat per lo rey, per los bandos, y el portaren a València mal y morí étich». Aierdi. J. 1999: 286.

${ }^{90}$ A las 10 horas de la mañana, concretamente. ACV. 691, Llibre de possessions..., f. 128. Al día siguiente recibió sepultura en el monasterio de Santa Tecla. ACV. Pahoner. J. III, ff. 392v-393.

${ }^{91}$ ACA. Consejo de Aragón. Leg. 582, doc. 46.

92 ACA. Consejo de Aragón. Leg. 586, doc. 24.

93 Aierdi. J. 1999: 282-283. 
religioso solicitó permiso para asistir a su anciana madre en Xàtiva. ${ }^{94}$ El nuevo Virrey, don Vespasiano Manrique de Lara Gonzaga, conde consorte de Paredes, se opuso por todos los medios, vetando que «este sujeto vuelva al reyno y menos a Xàtiva, porque siendo aquella ciudad una en la que más delitos han sucedido, ahora está mui quieta y sin parcialidades, y si buelve don Constantino es vastante para inquietarla». Nadie olvidaba su participación en la muerte de Ferrer y en otros crímenes de igual o peor calidad.

«lo que he sabido deste sujeto... es el ser de mui mala calidad. Que ha perpetrado graves delitos siendo religioso dominico, como son el haver dado una acuchillada al confessor de las monjas de Onteniente porque ablava a una de ellas con quien lo hazía don Constantino. El haverse hallado con don Vizente Fejedos y otros doze u treze en una resistencia hecha a la redada del Justicia de Xàtiva, arcabuzeándose, y murió uno de sus compañeros. Y de aquí se siguió el aver fundado una quadrilla de todos y yr en camino bandidos, inquietando y perturbando la paz y quietud pública y formando parcialidades contra don Miguel Fenollet y otros, poniendo toda aquella ciudad y todos los lugares circumvezinos a punto de perderse; y fue forzoso enviar un ministro de la Real Audiencia, que estuvo más de dos meses en ajustarlo. Y prosiguiendo en sus inquietudes, fue preso y puesto en la cárceles públicas, en las quales, con otros presos, trataron la muerte del doctor Pedro Navarro y le cortaron una oreja y se la emvió a los que le mandaron hacer el asesinato». ${ }^{95}$

Con estas últimas diligencias se dio por archivado el asesinato del chantre. Pero no las ramificaciones de los bandos en la primera iglesia del Reino. La Seo siguió sacudida hasta el final de la centuria por los movimientos estertóreos de un fenómeno que se resistía a desaparecer y cuyos ecos continuarían dejándose sentir en la vida catedralicia.

\section{BIBLIOGRAFÍA}

Aierdi. J. 1999. Dietari. Notícies de València i son regne, de 1661 a 1664 i de 1667 a 1679. A cura de V. J. Escartí. Barcelona: Barcino.

Arrieta. J. 1994. El Consejo Supremo de Aragón (1494-1707). Zaragoza: Fernando el Católico.

Callado Estela. E. 2003. Inmunidad eclesiástica y delincuencia en el siglo XVII. Los arzobispos de Valencia y la pacificación del Reino (1612-1699). Valencia: Biblioteca Valenciana.

- 2012. «Dignidades contra canónigos en la catedral de Valencia durante el siglo XVII». Estudis 38: 117-138.

\footnotetext{
${ }^{94}$ ACA. Consejo de Aragón. Leg. 603, s. d.

${ }^{95}$ Ibídem, docs. 41 / 1-41/ 7.
} 
y Esponera Cerdán. A. 2004. Memoria escrita, historia viva. Dos dietarios valencianos del Seiscientos. Valencia: Ayuntamiento de Valencia.

Canet Aparisi. T. 1990. La Magistratura valenciana (siglo XVI-XVII). Valencia: Universitat de València.

Casey. J. 1970 «La crisi general del segle XVII a València, 1646-1648». Boletín de la Sociedad Castellonense de Cultura XLVI: 96-173.

- 1983. El Reino de Valencia en el siglo XVII. Madrid: Siglo XXI.

- 1988. «Bandos y bandidos en la Valencia Moderna», en Homenatge al doctor Sebastià Garcia Martínez: I 407-421. Valencia: Generalitat Valenciana.

Cereceda. F. 1944. «El litigio de los cabildos y su repercusión en las relaciones con Roma (1551-1556)». Razón y fe 130: 215-234. Istmo.

Domínguez Ortiz. A. 1985. Las clases privilegiadas en el Antiguo Régimen Madrid:

Esquerdo. O. 2002. Nobiliario valenciano. Valencia: Biblioteca Valenciana.

Felipo Orts. A. 1988. El centralismo de nuevo cuño y la política de Olivares en el País Valenciano. Valencia: Ayuntamiento de Valencia.

Ferrero Micó. R. 1985. «Bandosidades nobiliarias en Valencia durante la época foral», Saitabi XXXV: 95-110.

García Cárcel, R. 1980. Herejía y sociedad en el siglo Xvi. La Inquisición en Valencia 1530-1609. Barcelona: Península.

García Martínez. S. 1980. Bandolers, corsaris i moriscos. Valencia: Tres i Quatre.

- 1991. Valencia bajo Carlos II: Bandolerismo, reivindicaciones agrarias y servicios a la Monarquía. Valencia: Ayuntamiento de Villena.

Goñi Gatzambide. J. 1975. «Los cabildos españoles y la confirmación del concilio de Trento». Annuarium Historiae Conciliorum 7: 425-458.

Guía Marín. Ll. J. 1975. «Los estamentos valencianos y el duque de Montalto: los inicios de la reacción foral». Estudis 4: 129-146.

- 1980. «La Guerra de Cataluña y el bandolerismo valenciano (1640-1652)», en $I^{\text {er }}$ Colloque sur le Pays Valencien a l'époque moderne: 117-141. Pau: s.e.

- 1984. «Dissidència política i repressió social al País Valencià a mitjan segle XVII». Saitabi XXXIV: 105-124.

- 1994 «Rebels i marginats en el segle XVII valencià», en La Segona Germania. Col·loqui Internacional, Valencia: 65-132. Valencia: Diputació de València.

- 2002. «Dona, honor i bandolerisme: els desordres de l'Almirall d'Aragó en la València del segle XVII». Estudis 28: 287-315.

- 2003. «Bandoleros, rebeldes y marginados: Mateu Vicent Benet y las bandositats valencianas», en Banditismi mediterranei (secoli XVI-XVII): 87-106. Cerdeña. 
Guitarte Izquierdo. V. 1985. Obispos auxiliares en la historia del arzobispado de Valencia. Castellón: Ayuntamiento de Castellón.

Haliczer. S. 1993. Inquisición y sociedad en el reino de Valencia (1478-1834). Valencia: Alfons el Magnànim.

Marín Martínez. T. 1948. «Primeras repercusiones tridentinas: el litigio de los cabildos españoles. Su proceso en la diócesis de Calahorra», Hispania Sacra 1: 325-349.

Mansilla. D. 1957. «Reacción del cabildo de Burgos ante las visitas y otros actos de jurisdicción intentados por sus obispos». Hispania Sacra X: 135-159.

Pérez Villanueva, J. Escandell Bonet, B. (Dirs.) 2000. Historia de la Inquisición en España y América III. Temas y problemas. Madrid: BAC.

Pons Alós. V. 1982. El fondo Crespí de Valldaura en el Archivo Condal de Orgaz (1249-1548). Valencia: Universitat de València.

- 1990. Los Crespí de Valldaura y l'Alcúdia de Crespíns. L’Alcúdia de Crespíns: Associació d'Amics de l'Ermita de Sumacàrcer.

- 1995. El señorío de Sumacàrcer en la Baja Edad Media. De mudéjares a moriscos. Sumacàrcer: L'Alcúdia de Crespíns: Associació d'Amics de l'Ermita de Sumacàrcer.

- 1999. El señorío de Sumacárcer en el siglo XVII: la expulsión de los moriscos y la repoblación cristiana. Sumacàrcer: L'Alcúdia de Crespíns: Associació d'Amics de l'Ermita de Sumacàrcer.

Salvador Lizondo. $\mathrm{M}^{\mathrm{a}}$ D. 1986. Los virreinatos de los duques de Maqueda y Segorbe (1553-1563). Configuración del bandolerismo, presión islámica y problemática de sus gobiernos, Tesis doctoral inédita. Valencia: Universitat de València.

Vila López, M. 1984. Bandolerismo y piratería (1635-1645) en el reino de Valencia, durante el reinado de Felipe IV. Valencia: Universitat de València. 